\title{
C08
}

\section{Structural Controls on Leakage from a Natural CO2 Geologic Storage Site - Central Utah, USA}

\author{
B. Dockrill (Chevron) \& Z.K. Shipton* (University of Glasgow)
}

\section{SUMMARY}

We present outcrop studies of a leaky natural $\mathrm{CO} 2$ accumulation in central Utah, U.S.A. The fluid migration history through the faulted stratigraphy is established from field relationships. Fluids charged and diffused through a carrier bed, migrating up-dip to pool in the structural high created by the faulted, Green River Anticline. The fault forms a lateral seal, while overlying clay-rich cap rocks provide a transient top seal. Fractures in the damage zone to the fault compromise the sealing integrity of this top seal and enable vertical migration of fluids, preferentially around structurally complexities where the fracture network is most intense. The fluids subsequently charge a shallower sand-rich carrier bed and the process continues through the faulted sequence. The dependence of folding and fault-associated fracture permeability is paramount in controlling fluid flow in the study area and emphasizes the influence structure plays on the migration of fluids in sedimentary basins. These results emphasise the need for detailed fault analysis of structures within future engineered $\mathrm{CO} 2$ storage sites, and consideration of the burial history and timing of fault activity to assess the risk of $\mathrm{CO} 2$ leakage through cap rocks, fault cores and fault damage zones. 


\section{Fault and Top Seals \\ Montpellier 2009}

\section{Introduction}

Geological reservoirs used for $\mathrm{CO}_{2}$ storage must have the capacity to safely isolate $\mathrm{CO}_{2}$ from the atmosphere and near surface for thousands of years. Both natural (leaky cap rocks or fault seals) and man-made (boreholes) features could compromise the integrity of potential $\mathrm{CO}_{2}$ storage sites. Sites where natural $\mathrm{CO}_{2}$ has accumulated in geologic reservoirs can be used as natural analogues to understand the controls on $\mathrm{CO}_{2}$ storage and leakage in these systems.

\section{Field area and present-day leakage}

We present outcrop studies of a natural leaky $\mathrm{CO}_{2}$ accumulation in the Paradox Basin, central Utah, U.S.A. Faulting of the north-plunging Green River Anticline has created structural highs in the footwalls of the west-north-west trending Little Grand Wash Fault and northern fault of the Salt Wash Graben (Shipton et al., 2004; 2005). Accumulation of $\mathrm{CO}_{2}$-charged groundwater occurs in the high-porosity aeolian Navajo Sandstone, the top of which lies $\sim 800 \mathrm{~m}$ below the surface. This is capped by a low permeability sequence of marine carbonates, shales and sandstones. Focussed surface leakage of $\mathrm{CO}_{2}$ occurs in the immediate footwalls of both faults with the presence of $\mathrm{CO}_{2}$-charged geysers and springs and travertine deposits. Uncapped and corroded boreholes that penetrate the footwall aquifers also provide direct conduits for $\mathrm{CO}_{2}$ migration.

\section{Evidence for past fault-related fluid flow}

Field mapping, thin section and isotope studies indicates a protracted history of fluid flow along these faults. The presence of ancient travertines is evidence for past surface leakage. Iron-oxide reduction of the mid Jurassic sandstones, hydrocarbon-staining and carbonate and sulphate veining are evidence of deeper fluid flow. Hydrocarbon stained sandstones, and seeps close to the Little Grand Wash Fault suggest hydrocarbon migration from the early Tertiary to present. Iron-oxide reduction prevalent in the footwalls of both faults may be related to this hydrocarbon migration or a later fluid phase. Sulphate veins accompanied or followed iron-oxide reduction and precipitated from sulphate-rich meteoric waters (gypsum) or rising Pennsylvanian-source brines (celestine). Carbonate veins were precipitated from the same carbonate-rich fluids that precipitated the travertines at the surface. Spatial associations between the fault-related mineralization and diagenetic features suggest all the fluids used the same migration pathways through the faulted stratigraphy.

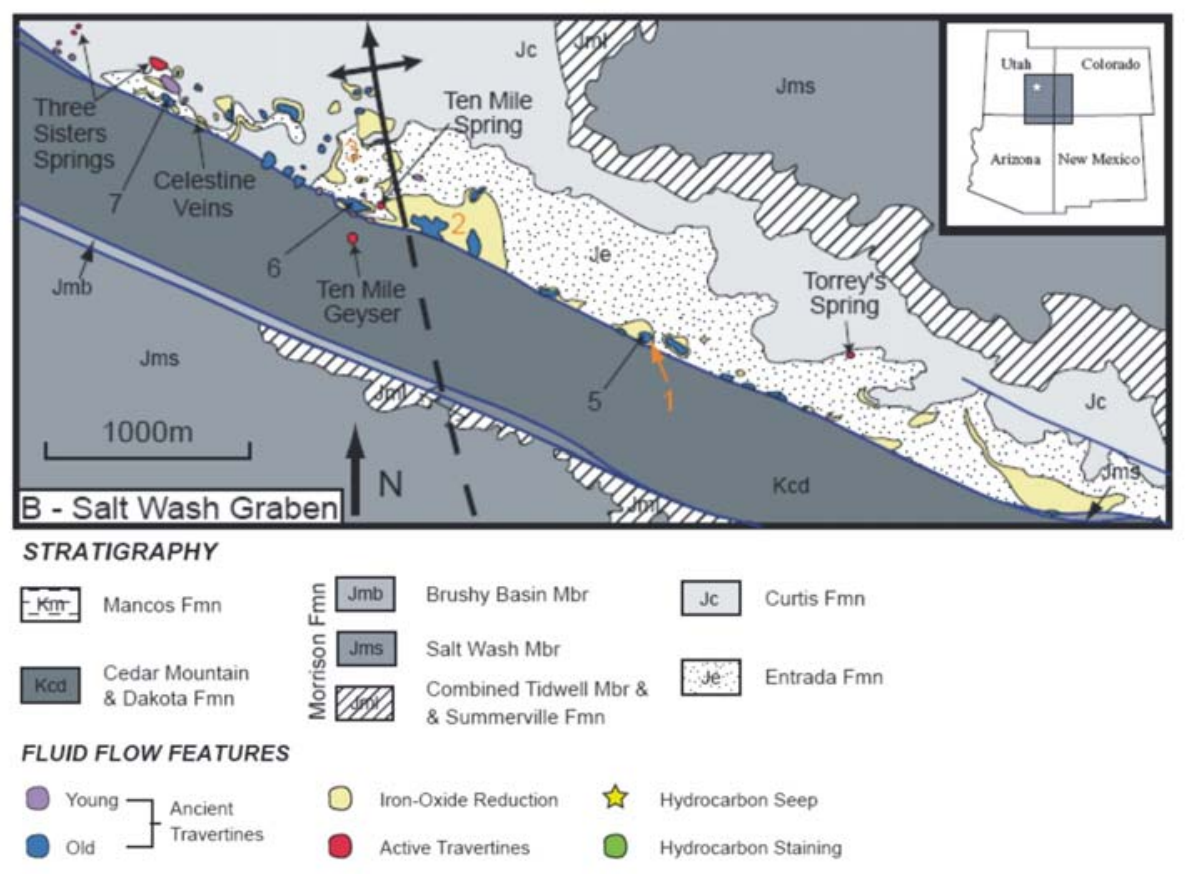

Map of travertine deposits and mineral alteration in the footwall to the northern fault of the Salt Wash Graben. Inset shows the location of the field site (star). 


\section{Fault and Top Seals \\ Montpellier 2009}

The spatial distribution of mineralization and diagenesis in varied footwall lithologies define the migration pathways of fluids in the faulted stratigraphy (Figure 1). In sand rich formations (Entrada and Curtis sandstones) prevalent in the northern footwall of the Salt Wash Graben, pervasive iron-oxide reduction and numerous travertine deposits extend into the footwall around the fold axis of the Green River Anticline. This distribution is consistent with fluids migrating up-dip and pooling at the crest of the faulted anticline. Away from this area, ironoxide reduction and travertine precipitation is limited to the immediate footwall suggesting fracture networks developed in the damage zone of the fault control the migration of fluids. This is readily evident in the clay-rich formations (Summerville and Morrison) of the Little Grand Wash Fault footwall, where travertine precipitation and diagenesis (i.e. iron-oxide reduction and hydrocarbon staining) is restricted to the immediate footwall, preferentially around structural complexities (i.e. relay zones and fault bends) where the fracture network is most intense. Therefore, upon the migration of fluids to the crest of the fault anticline, fluids vertically migrate through low-porosity, clay-rich units by utilising the fracture network developed in the damage zone of the fault.

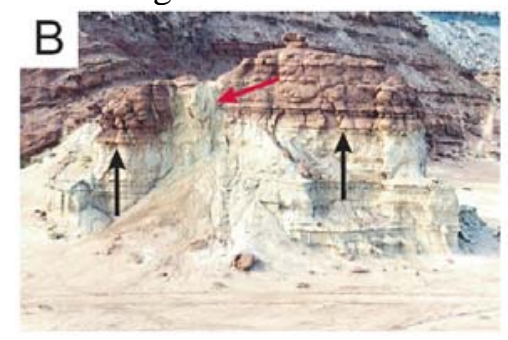

Exposure of Entrada sandstone butte with lower half completely reduced and upper half only reduced around a fracture cluster (red arrow). Note reduction is not bed confined with a varying upper contact (cf. black arrows). Height of butte approximately $18 m$.

\section{Fault sealing}

Field data and fault analyses show that both faults provide effective lateral seals to prevent cross-fault flow of $\mathrm{CO}_{2}$ due to lithological juxtapositions and/or development of concentrations of clay-rich fault gouge at all of the likely reservoir cutoffs. Conversely, high fracture densities developed in the footwall damage zones of both faults, particularly at sites of structural complexity, provide vertical conduits for $\mathrm{CO}_{2}$ to migrate through overlying, argillaceous cap rocks and charge shallower fault-bounded aquifers, and eventually to reach the surface.

\section{Summary}

Our results emphasise that fault damage zones can play a fundamental role in providing vertical conduits for fluids to escape through low permeability cap rocks. No algorithm exists to predict along-fault flow in a fractured damage zone, and cap rock integrity in the damage zone is likely to be dependent on burial history and timing of fault activity. Further case studies of fault-sealed $\mathrm{CO}_{2}$ reservoirs are required to calibrate fault sealing techniques to $\mathrm{CO}_{2}$. These results emphasise the need for detailed fault analysis of structures within future engineered $\mathrm{CO}_{2}$ storage sites, and consideration of the burial history and timing of fault activity to assess the risk of $\mathrm{CO}_{2}$ leakage through cap rocks, fault cores and fault damage zones.

\section{References}

Shipton, Z.K., Evans, J.P., Kirchner, D., Kolesar, P.T., Williams, A.P, Heath, J.E. [2004] Analysis of $\mathrm{CO}_{2}$ leakage through "low-permeability" faults from natural reservoirs in the Colorado Plateau, Southern Utah, in Baines, S.J., R.H. Worden, ed., Geological Storage of Carbon Dioxide, Geological Society of London Special publications 233, p. $43-58$.

Shipton, Z.K., Evans J.P., Dockrill, B., Heath, J.E., Williams, A.P., Kirchner, D., Kolesar, P.T. [2005] Natural leaking $\mathrm{CO}_{2}$-charged systems as analogs for failed geological storage reservoirs, in Benson, S.M., ed., Carbon Dioxide Capture for Storage in Deep Geologic Formations- Results from the $\mathrm{CO}_{2}$ Capture Project, Volume 2: Geologic storage of Carbon Dioxide with Monitoring and Verification: London, Elsevier, p. 699- 712.

Acknowledgements Funding for this work came from The Carbon Capture Project and the Trinity College Broad Curriculum Initiative. 